\title{
Predicting the Final Cost of Iraqi Construction Project Using Artificial Neural Network (ANN)
}

\author{
Abbas Mahde Abd ${ }^{1}$, Nidal Adnan Jasim² and Fatima Saleh Naseef2* \\ ${ }^{1}$ Architectural Engineering Department, College of Engineering, University of Diyala, Iraq; abbas.mahde@gmail.com \\ ${ }^{2}$ Department of Civil Engineering, College of Engineering, University of Diyala, Iraq; \\ nidaladnan100@gmail.com, fatimasaleh5420@gmail.com
}

\begin{abstract}
Objectives: It is very hard estimated the budget of construction projects at the first step of the building because of the limited data about the project at this step. Developing a mathematical equation to estimate the budget of the Iraqi construction project at initial step is the aim of this study. Method: It involves using of Artificial Neural Network (ANN) to develop the mathematical equation. The researchers collected the information about cost for 501 sets project for the duration (2005-2015). The total costs of 25 activity of construction work such as (excavation the foundation works, Landfill works, filling with sub-base works, Construction works under moisture proof layer, Construction works above moisture proof layer, Construction works of sections, ordinary concrete for walkways, reinforced concrete foundation, reinforced concrete column, reinforced concrete lintel, reinforced concrete slabs, reinforced concrete beams, reinforced concrete stair, reinforced concrete for the sun bumper, plaster finishing works, cement finishing works, Plastic Paints, Pentellite paints, pigment color, Stone packaging, Works of placing marble, Ceramic works for floor, Ceramic works for walls, Flattening (two opposite layers of lime), Flattening (Tiling)) are utilized for cost prediction. Findings: The results of the correlation factor equal to $(100 \%)$, the percentage of error equal (5.81\%) and amount of precision was $(94.19 \%)$ which indicated that the artificial neural network gives very good performance in prediction construction cost. Applications: ANN is proved useful in estimating the costs of construction well in advance especially when the data are incomplete or limited.
\end{abstract}

Keywords: Artificial Neural Network, Construction Project, Cost Estimate, Cost Estimation Model

\section{Introduction}

The essential thing for construction managers is the budget of the construction; if the project completed with the same determined budget, time and quality required, the project considered successful ${ }^{1}$. Planning the project in an inappropriate manner or put insufficient budget and time, construction project subject to failure ${ }^{2}$. Therefore, a correct estimation of the budget of construction is a key element for profit ${ }^{3}$. Cost estimation assists the owners and planners in assessing the purpose of building project and controls costs successfully ${ }^{4}$. Project managers were interested in estimating the cost of construction because of the importance of the subject, especially in the first stages of the work when the data is incomplete $e^{2}$. So, cost prediction is considered a key element in decision-making.
Due to important and difficulty of cost estimation, many researchers look for either traditional or artificial intelligence methods and examined for their validity in predicting the budget of construction work at the first step. A new method has recently emerged based on computer systems and simulating the human brain namely Artificial Neural Networks (ANN) ${ }^{5}$. This technique is characterized by the other techniques, such as regression analysis technology, the ability to deal with the most complex cases ${ }^{6}$. In addition, it can approximate functions well without explanation them that means the outputs are produced based on several input signals and through training those networks, accurate estimates can be made ${ }^{7}$.

First research wrote by ${ }^{8}$ studied the ANN uses in the civil engineering department. This research encouraged many researchers into the use in the construction sector.

*Author for correspondence 


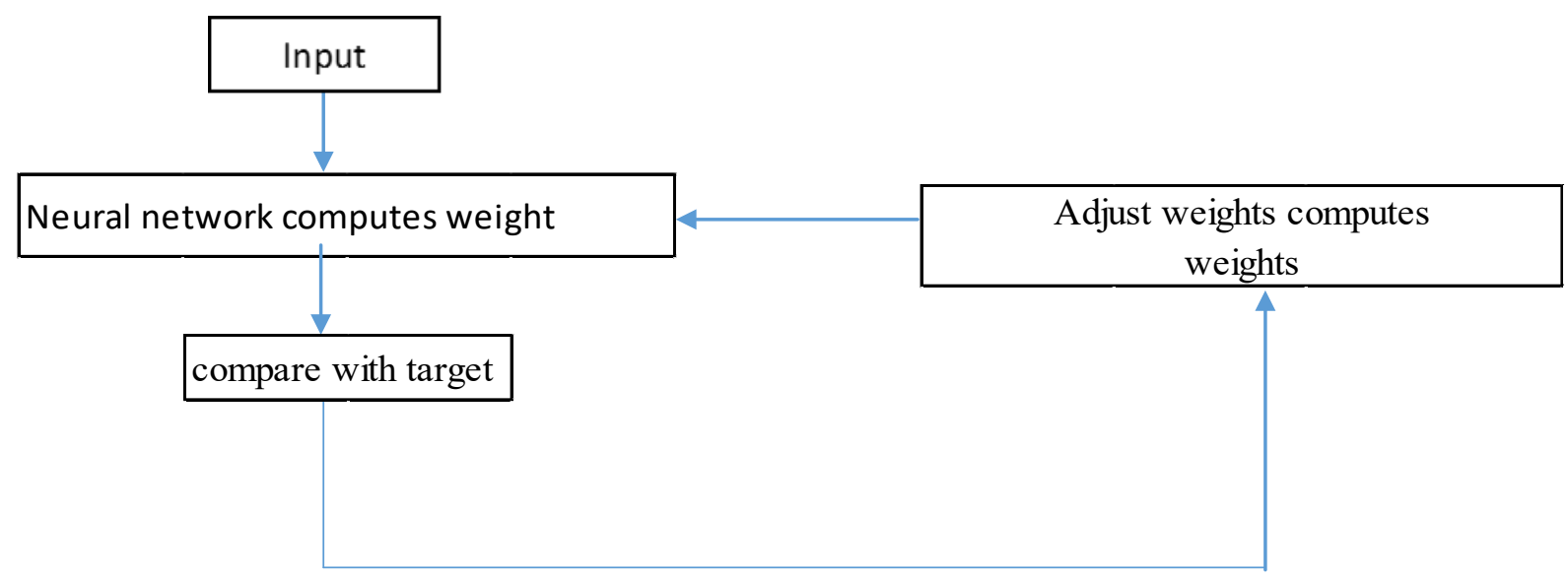

Figure 1. Correction of error by using target data $a^{\frac{18}{}}$.

$\mathrm{In}^{9}$ used two types of neural network such machine learning the general regression neural network GRNN and multiple layer feed-forward networks MLFN to predict road tunnel construction cost. The researcher made a comparison between these models with real quantities and costs to check the accuracy. They found the GRNN model more accurate than MLFN model. The main weakness of this research not taking into account the factors that affect construction projects such as duration and tendering method.

$\mathrm{In}^{10}$ used ANNs with back propagation algorithm to estimate the cost of structure works for the highway project. In this research, the researcher checked the ability of this technique in prediction costs. The researcher determined many variables that effect on the highway project as inputs to develop the prediction model. The researcher found the ANNs model gave very good performance in predicting the budget of highway projects.

$\mathrm{In}^{11}$ use ANN to develop a model used to predict the budget expressway. To build the model, the researcher used 169 building projects were gathered from the construction industry in the Gaza Strip. At the last, the researcher concluded that ANN proved it's the ability in calculating the budget of highway construction projects with high performance.

$\mathrm{In}^{12}$ used ANN to create mathematical equation used to determine the budget of the expressway projects. The researcher collected his data Stat Commission for Roads and Bridges in Iraq. At last, this technique gives very good result in predicting the budget of expressway project according to correlation factor and the precision of model.

\section{Overview on Artificial Neural Network}

Artificial neural networks consist of several components such as connection neurons or nodes, the output layer function, transfer function, the activation rule, the propagation rule, the connectivity pattern, the learning rule and the environment in which the system work ${ }^{13}$. The interconnected neurons that are trained using a set of data to select the base pattern. Neural networks contain a numbers of layers contained a number of neurons such as the inputs layer, hidden layer, and the outputs layer. The network receives the data through the first layer which is the input layer, and then the data is transferred to the second layer, which is hidden layer by the weights that connect the nodes. The information is then transferred to the last layer which is the output layer, where offers the result in this layer. Input data are weighted to indicate how much it impacts on the output data. Inputs that have a larger weight have a higher impact, transfer function is then applied to the weighted inputs, to produce the output signals by altering the inputs. The first layer includes one or more nodes describe various parameters where every input nodes represent as an inputs to the second layer. The second layer contains a number of nodes which determine the weighted summation of the input data.

Figure 1 demonstrates the work of neural networks in the modernization of weights and biases by comparing the real output with the desired. After gaining experience with a number of iteration Network, weights are adjusting $\frac{13}{}$. Neural networks are used for many 
purposes such as solve the classification problem, function approximation, predicting, clustering/categorizing, function approximation, optimization, control, and content-addressable memory ${ }^{14}$.

\section{Development of ANN model}

This study attempts to overcome some of the difficulties found in neural network technology for the purpose of using it effortlessly in the field in the field of construction and to build an accurate cost prediction model. The organization of the network comprises of three layer, ANNs should be built in an orderly manner to make the network work in height efficiently by addressing key network factors such as the selection of model inputs and outputs, Splitting and Scaling the data, determination the structure of the network, training the network, and validity the model 1 .

\section{ANN Model Inputs and output}

The model input variables for cost estimation model were consisting of twenty-five parameters symbol by $x$ is the cost of excavation the foundation works, Landfill works, filling with sub-base works, Construction works under moisture proof layer, Construction works above moisture-proof layer, Construction works of sections, ordinary concrete for walkways, reinforcement foundation, reinforcement concrete column, reinforcement lintel, reinforcement slabs, reinforcement beams, reinforcement stair, reinforcement concrete for the sun bumper, plaster finishing works, cement finishing works, Plastic Paints, Pentellite paints, pigment color, Stone packaging, Works of placing marble, Ceramic works for floor, Ceramic works for walls, Flattening (two opposite layers of lime), Flattening (Tiling). The construction cost is determined as the output variable (dependent variable) and the observations consist of the individual projects. An effort is performed to formulate an equation including input variables predicting the costs of every project.

\section{Data Division for ANN Model}

Training, testing and validation set is the three splittings of data. Data is splitting by trials and errors to get the lowest errors and top coefficient of correlation. The division performed in the Matlab software. The selection of the neural network depends on the good results that the network gave with respect to training and testing error and coefficient of correlation.

The researcher found the best divisions are $70 \%$ of data for the training and $20 \%$ for the testing and $10 \%$ for validation. In this research, the method of learning that use for the network is the supervised learning because the input data with outputs are available so by training the network can learn to know the relation between inputs and outputs. The essential process in building the ANN model is determining the number of hidden layers and its nodes ${ }^{16}$. By made many trials, the researchers' utilized single hidden layer with two hidden nodes to develop the estimation model.

\section{Scaling of Data}

The main objective of scaling data is to confirm that data take the same attention during the training process and to eliminate their dimension. Data is limited between 0.0 to 1.0 if the sigmoid activation function used in the hidden and output layer and limited between -1.0 to 1.0 if the Tanh activation function is used ${ }^{17}$. The scaled equation $S$ can be express by the following:

$$
S=(x-x \min ) /(x \max -x \min )
$$

Where $x$ is original value of variable

\section{Model Architecture, Optimization and Stopping Criteria}

The difficult and essential process in the building of neural model is the definition of the aarchitecture of the neural network. The technique must be training several times to get the lowest error rate and the highest correlation of validation or testing data set, by choosing the appropriate features of model, such as the number of hidden layer and its nodes, momentum terms, learning rates, and activation function.

The researcher believed the optimal network of cost estimation model that give minimal testing and training errors and highest coefficient of correlation consists of two hidden nodes and when sigmoid activation function was used for hidden and outputs layer. 


\section{ANN Model Final Equations}

The connection weights between layers and threshold levels (bias) are summarized in Table 1

$\mathrm{Y}=1 /\left(1+\mathrm{e}^{\wedge}(-(3.1061-3.2144 \tanh (\mathrm{y} 1)+3.2079\right.$ $\tanh (\mathrm{y} 2))))$

$\mathrm{Y} 1=\{\theta 26+(\mathrm{w} 26-1 * \mathrm{x} 1)+(\mathrm{w} 26-2 * \mathrm{x} 2)+(\mathrm{w} 26-$ $3 * \mathrm{x} 3)+(\mathrm{w} 26-4 * \mathrm{x} 4)+(\mathrm{w} 26-5 * \mathrm{x} 5)+(\mathrm{w} 26-6 *$ $\mathrm{x} 6)+(\mathrm{w} 26-7 * \mathrm{x} 7)+(\mathrm{w} 26-8 * \mathrm{x} 8)+(\mathrm{w} 26-9 * \mathrm{x} 9)+$ $(\mathrm{w} 26-10 * \mathrm{x} 10)+(\mathrm{w} 26-11 * \mathrm{x} 11)+(\mathrm{w} 26-12 * \mathrm{x} 12)$

$+(\mathrm{w} 26-13 * \mathrm{x} 13)+(\mathrm{w} 26-14 * \mathrm{x} 14)+(\mathrm{w} 26-15 * \mathrm{x} 15)$

$+(\mathrm{w} 26-16 * \mathrm{x} 16)+(\mathrm{w} 26-17 * \mathrm{x} 17)+(\mathrm{w} 26-18 * \mathrm{x} 18)$

$+(\mathrm{w} 26-19 * \mathrm{x} 19)+(\mathrm{w} 26-20 * \mathrm{x} 20)+(\mathrm{w} 26-21 *$

$\mathrm{x} 21)+(\mathrm{w} 26-22 * \mathrm{x} 22)+(\mathrm{w} 26-23 * \mathrm{x} 23)+(\mathrm{w} 26-24$

$* \mathrm{x} 24)+(\mathrm{w} 26-25 * \mathrm{x} 25)\}$

$\mathrm{Y} 2=\{027+(\mathrm{w} 27-1 * \mathrm{x} 1)+(\mathrm{w} 27-2 * \mathrm{x} 2)+(\mathrm{w} 27-3$

$* \mathrm{x} 3)+(\mathrm{w} 27-4 * \mathrm{x} 4)+(\mathrm{w} 29-5 * \mathrm{x} 5)+(\mathrm{w} 27-6 * \mathrm{x} 6)$

$+(\mathrm{w} 27-7 * \mathrm{x} 7)+(\mathrm{w} 27-8 * \mathrm{x} 8)+(\mathrm{w} 27-9 * \mathrm{x} 9)+$

$(\mathrm{w} 27-10 * \mathrm{x} 10)+(\mathrm{w} 27-11 * \mathrm{x} 11)+(\mathrm{w} 27-12 * \mathrm{x} 12)$

$+(\mathrm{w} 27-13 * \mathrm{x} 13)+(\mathrm{w} 27-14 * \mathrm{x} 14)+(\mathrm{w} 27-15 *$

$\mathrm{x} 15)+(\mathrm{w} 27-16 * \mathrm{x} 16)+(\mathrm{w} 27-17 * \mathrm{x} 17)+(\mathrm{w} 27-18$

$* \mathrm{x} 18)+(\mathrm{w} 27-19 * \mathrm{x} 19)+(\mathrm{w} 27-20 * \mathrm{x} 20)+(\mathrm{w} 27-$

$21 * \mathrm{x} 21)+(\mathrm{w} 27-22 * \mathrm{x} 22)+(\mathrm{w} 27-23 * \mathrm{x} 23)+(\mathrm{w} 27$

$-24 * \mathrm{x} 24)+)+(\mathrm{w} 27-25 * \mathrm{x} 25)\}$

It is necessary to limit all inputs data between ( 0 and 1$)$ before use Equation (3) and (4), by utilizing Equation (1) and use the range of training data in Table 2. The value extracted from the Equation (2) is the estimated value of the cost is also must be limited between ( 0 and 1$)$ by Equation (1) and the range of inputs and outputs in the Table 2 to get the actual value. By scaling and entering the information of the network in the Table (2), Equations (2) and (3) and (4) can be modified as showed below:

$\mathrm{Y}=4.1376 /\left(1+\mathrm{e}^{\wedge}(-(3.1061-3.2079 \tanh (\mathrm{y} 1)+3.2079\right.$

$\tanh (\mathrm{y} 2))))+7.7724$

$\mathrm{Y} 1=\{0.0679+(4.15042 \mathrm{E}-10 * \mathrm{x} 1)+(2.1796 \mathrm{E}-08$

$* \mathrm{x} 2)+(1.50925 \mathrm{E}-08 * \mathrm{x} 3)+(-9.07722 \mathrm{E}-09 * \mathrm{x} 4)$

$+(1.10181 \mathrm{E}-09 * \mathrm{x} 5)+(-9.04671 \mathrm{E}-08 * \mathrm{x} 6)+$

$(-7.95008 \mathrm{E}-09 * \mathrm{x} 7)+(7.889636711 * \mathrm{x} 8)+(4.73359 \mathrm{E}$

$-09 * \mathrm{x} 9)+(-1.0063 \mathrm{E}-08 * \mathrm{x} 10)+(1.64803 \mathrm{E}-09$

$* \mathrm{x} 11)+(-3.88695 \mathrm{E}-08 * \mathrm{x} 12)+(-8.85867 \mathrm{E}-08$

$* \mathrm{x} 13)+(8.15341 \mathrm{E}-09 * \mathrm{x} 14)+(3.35171 \mathrm{E}-12 *$

$\mathrm{x} 15)+(3.22401 \mathrm{E}-08 * \mathrm{x} 16)+(-2.6512 \mathrm{E}-09 * \mathrm{x} 17)$

$+(-1.68278 \mathrm{E}-07 * \mathrm{x} 18)+(-5.85897 \mathrm{E}-08 * \mathrm{x} 19)$

$+(4.6794 \mathrm{E}-08 * \mathrm{x} 20)+(4.83987 \mathrm{E}-09 * \mathrm{x} 21)+$
$(-7.73854 \mathrm{E}-08 * \mathrm{x} 22)+(-1.04134 \mathrm{E}-10 * \mathrm{x} 23)+$

$(7.92797 \mathrm{E}-08 * \mathrm{x} 24)+(2.30057 \mathrm{E}-09 * \mathrm{x} 25)\}$

$\mathrm{Y} 2=\{-4.9575+(7.31034 \mathrm{E}-08 * \mathrm{x} 1)+(-5.80315 \mathrm{E}$

$-09 * \mathrm{x} 2)+(-1.34782 \mathrm{E}-07 * \mathrm{x} 3)+(-1.90056 \mathrm{E} 09 *$ $\mathrm{x} 4)+(4.31584 \mathrm{E}-09 * \mathrm{x} 5)+(-1.91576 \mathrm{E}-08 * \mathrm{x} 6)+$

$(1.08618 \mathrm{E}-08 * \mathrm{x} 7)+(-2.47533 \mathrm{E} 09 * \mathrm{x} 8)+(7.87023 \mathrm{E}$ $-08 * \mathrm{x} 9)+(3.82913 \mathrm{E}-10 * \mathrm{x} 10)+(-3.11741 \mathrm{E}-09 *$

$\mathrm{x} 11)+(-7.66564 \mathrm{E}-09 * \mathrm{x} 12)+(1.82317 \mathrm{E}-07 * \mathrm{x} 13)+$

$(2.91136 \mathrm{E}-09 * \mathrm{x} 14)+(7.9924 \mathrm{E}-11 * \mathrm{x} 15)+(1.3336 \mathrm{E}$

$-09 * \mathrm{x} 16)+(4.71763 \mathrm{E}-08 * \mathrm{x} 17)+(-1.21211 \mathrm{E}-08$

$* \mathrm{x} 18)+(2.92125 \mathrm{E}-07 * \mathrm{x} 19)+(1.14073 \mathrm{E}-09 *$

$\mathrm{x} 20)+(-8.03621 \mathrm{E}-09 * \mathrm{x} 21)+(3.45464 \mathrm{E}-10 * \mathrm{x} 22)$

$+(3.88375 \mathrm{E}-10 * \mathrm{x} 23)+(1.21089 \mathrm{E}-09 * \mathrm{x} 24)+$

$(-5.55862 \mathrm{E}-09 * \mathrm{x} 25)\}$

\section{Validity of the Cost Estimation Model}

1. Determination Factor R.

2. Correlation Factor R.

3. Mean Absolute Percentage Error (MAPE),

$$
\text { MAPE }=\left(\left(\sum_{i=1}^{n o}|R-P| / R\right) / n\right) * 100 \%
$$

Where:

$\mathrm{R}=$ Real value.

$\mathrm{P}=$ Prediction value.

no $=$ numbers of validation data.

4. Percent of accuracy average

(AA \%) AA $\%=100 \%-$ MAPE

The Table 3 shows the results of the artificial neural network model where value $\%$ AA was $(94.19 \%)$ and MAPE was (5.81\%). So the researcher found that ANN estimation model gives a very good performance.

The logarithm of prediction cost values was drawn with the logarithm of actual values for data of validation to validate the prediction model as shown in Figure 2. It is clear from this figure the generalization capability of ANNs techniques using the data of validation. Determination factor $\left(\mathrm{R}^{2}\right)$ is $(98.7 \%)$, so the researcher concluded that ANNs model (estimation model) give excellent agreement with the actual measurements.

Figure 3 show the final real costs according to estimation cost for testing data. There is a small variance between the two costs. 


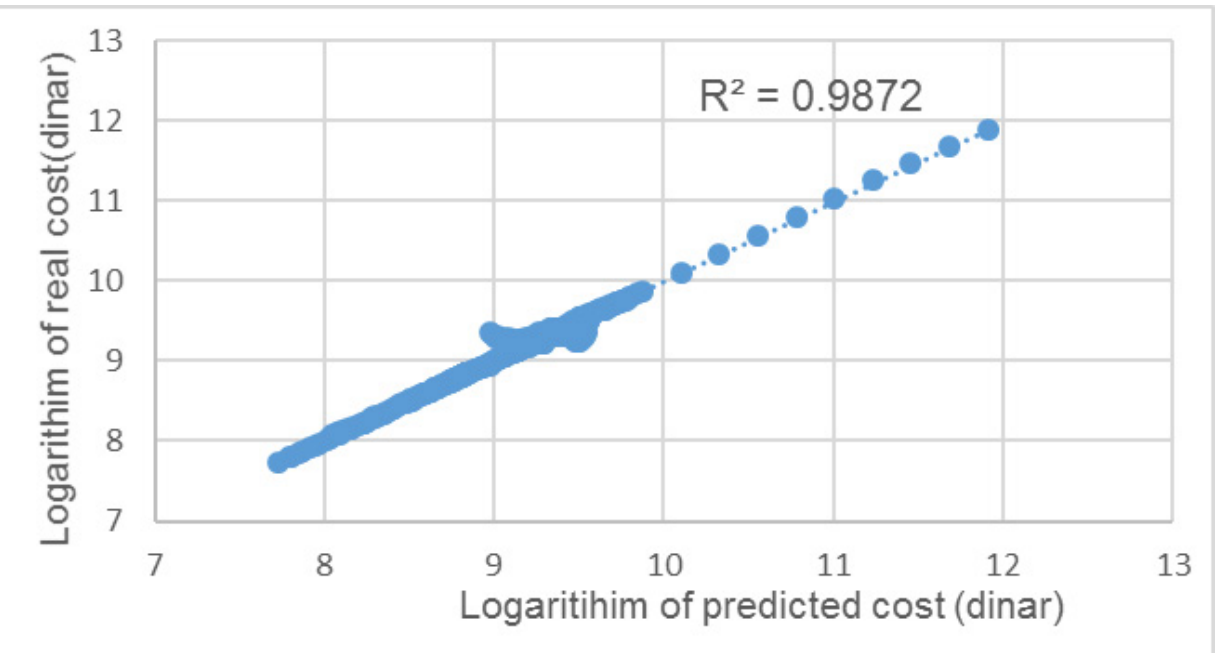

Figure 2. Prediction and real final cost for testing data.

Table 1. Weights and threshold levels for the ANN optimal model

\begin{tabular}{|c|c|c|c|c|c|}
\hline \multirow{2}{*}{ Hidden layer nodes } & \multicolumn{4}{|c|}{ Wij (weight connection in node $i$ in input layer to node $j$ in hidden layer) } & \multirow{2}{*}{ Hidden layer bias $\theta \mathbf{j}$} \\
\hline & $\mathrm{i} 1=0.0141$ & $\mathrm{i} 2=1.117$ & $\mathrm{i} 3=0.4436$ & $\mathrm{i} 4=-1.6339$ & \\
\hline \multirow{6}{*}{$j=26$} & i5 $=0.7305$ & $\mathrm{i} 6=-5.3267$ & $\mathrm{i} 7=-0.6116$ & $\mathrm{i} 8=-0.5772$ & \multirow{6}{*}{0.0679} \\
\hline & i9 $=0.6201$ & $\mathrm{i} 10=-3.5925$ & $\mathrm{i} 11=1.297$ & $\mathrm{i} 12=-0.7971$ & \\
\hline & $\mathrm{i} 13=-2.4007$ & $\mathrm{i} 14=1.435$ & $\mathrm{i} 15=0.1763$ & $\mathrm{i} 16=2.8962$ & \\
\hline & $\mathrm{i} 17=-0.2421$ & $\mathrm{i} 18=-8.57$ & $\mathrm{i} 19=-0.619$ & $\mathrm{i} 20=11.6049$ & \\
\hline & $\mathrm{i} 21=1.4568$ & $\mathrm{i} 22=-5.1521$ & $\mathrm{i} 23=-0.5769$ & $\mathrm{i} 24=3.8105$ & \\
\hline & i25 $=0.4003$ & & & & \\
\hline \multirow{7}{*}{$j=27$} & $\mathrm{i} 1=2.4835$ & $\mathrm{i} 2=2.4835$ & $\mathrm{i} 3=-3.9615$ & $\mathrm{i} 4=-0.3421$ & \multirow{7}{*}{-4.9575} \\
\hline & $\mathrm{i} 5=2.8614$ & $\mathrm{i} 6=-1.128$ & $\mathrm{i} 7=0.8356$ & $\mathrm{i} 8=-1.2946$ & \\
\hline & $\mathrm{i} 9=10.31$ & $\mathrm{i} 10=0.1367$ & $\mathrm{i} 11=-2.4534$ & $\mathrm{i} 12=-0.1572$ & \\
\hline & $\mathrm{i} 13=4.9408$ & $\mathrm{i} 14=0.5124$ & $\mathrm{i} 15=4.204$ & $\mathrm{i} 16=0.1198$ & \\
\hline & $\mathrm{i} 17=4.308$ & $\mathrm{i} 18=-0.6173$ & $\mathrm{i} 19=3.0863$ & $\mathrm{i} 20=0.2829$ & \\
\hline & $\mathrm{i} 21=-2.4189$ & $\mathrm{i} 22=0.023$ & $\mathrm{i} 23=2.1516$ & $\mathrm{i} 24=0.0582$ & \\
\hline & $\mathrm{i} 25=-0.9672$ & & & & \\
\hline \multirow{2}{*}{ Output layer nodes } & \multicolumn{4}{|c|}{ Wij (weight connection in node $\mathrm{i}$ in hidden layer to node $\mathrm{j}$ in output layer) } & \multirow{2}{*}{ output layer bias $\theta \mathbf{j}$} \\
\hline & $\mathrm{i}=26$ & $i=27$ & & & \\
\hline $\mathrm{j}=28$ & -3.2144 & 3.2079 & & & 3.1061 \\
\hline
\end{tabular}

Table 2. Input and output statistics for the ANNs model

\begin{tabular}{|c|c|c|c|}
\hline Variable & Max. & Min. & Range \\
\hline $\mathrm{x} 1$ & 34568800 & 596370 & 33972430 \\
\hline $\mathrm{x} 2$ & 1552000 & 1552000 & 51248000 \\
\hline $\mathrm{x} 3$ & 30890900 & 1498900 & 29392000 \\
\hline
\end{tabular}




\begin{tabular}{|c|c|c|c|}
\hline Variable & Max. & Min. & Range \\
\hline $\mathrm{x} 4$ & 184523200 & 27926000 & 179821600 \\
\hline $\mathrm{x} 5$ & 691400000 & 27926000 & 663474000 \\
\hline$x 6$ & 60000000 & 1120000 & 58880000 \\
\hline $\mathrm{x} 7$ & 78550000 & 1620000 & 58880000 \\
\hline $\mathrm{x} 8$ & 78550000 & 1620000 & 76930000 \\
\hline $\mathrm{x} 9$ & 533730000 & 10403000 & 523327000 \\
\hline $\mathrm{x} 10$ & 360000000 & 2568500 & 357431500 \\
\hline $\mathrm{x} 11$ & 791500000 & 4398000 & 787102000 \\
\hline $\mathrm{x} 12$ & 23720000 & 3212900 & 20507100 \\
\hline $\mathrm{x} 13$ & 29600000 & 2500000 & 27100000 \\
\hline $\mathrm{x} 14$ & 181106000 & 5500000 & 52568500000 \\
\hline $\mathrm{x} 15$ & 95381000 & 5548700 & 89832300 \\
\hline $\mathrm{x} 16$ & 97320000 & 6003000 & 91317000 \\
\hline $\mathrm{x} 17$ & 52784000 & 1856400 & 50927600 \\
\hline $\mathrm{x} 18$ & 10965000 & 400000 & 10565000 \\
\hline $\mathrm{x} 19$ & 248650000 & 943160 & 247706840 \\
\hline $\mathrm{x} 20$ & 312840000 & 11617000 & 301223000 \\
\hline $\mathrm{x} 21$ & 312840000 & 11617000 & 66577200 \\
\hline $\mathrm{x} 22$ & 5542000000 & 3736600 & 5538263400 \\
\hline $\mathrm{x} 23$ & 48063980 & 2023900 & 48063980 \\
\hline $\mathrm{x} 24$ & 180980000 & 6522200 & 48063980 \\
\hline $\mathrm{x} 25$ & 180980000 & 6522200 & 174457800 \\
\hline Log output & 11.91 & 7.7724 & 4.1376 \\
\hline
\end{tabular}

Table 3. Results of the ANN estimation model

\begin{tabular}{|l|c|c|c|c|}
\hline Description & MAPE & AA & R & $\mathbf{R}^{2}$ \\
\hline ANN Model & $5.81 \%$ & $94.19 \%$ & $100 \%$ & $98.7 \%$ \\
\hline
\end{tabular}

\section{Estimated cost Real cost}

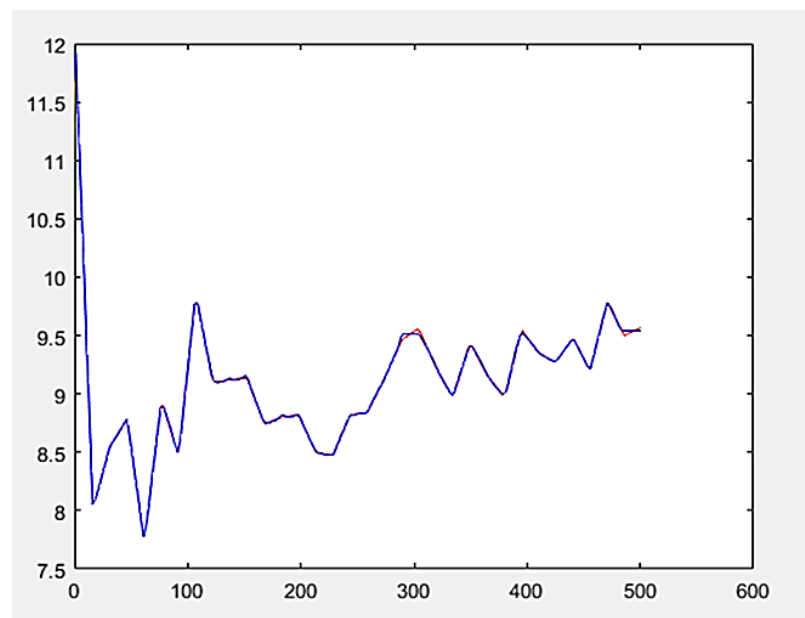

Figure 3. Designates the real cost with estimation costs for testing data sets. There is a small variance between the two costs. 


\section{Conclusions}

- Neural network technology has the ability to develop an efficient mathematical equation used to calculate the cost of the construction project in the initial stages of the life of the project, particularly when data is incomplete.

- The researchers built the neural network of three layers that include inputs layer, hidden layer and output layer. The first layer consist of twenty-five nodes represent the items of construction project, the second layer contains two hidden nodes and the last layer contain single node represent cost of construction cost.

The results included the following:

- Mean Absolute Percentage Error (MAPE) equal to $5.81 \%$.

- Average Accuracy Percentage (AA \%) equal to $94.19 \%$.

- Determination factor $\left(\mathrm{R}^{2}\right)$ equal to $98.7 \%$.

- Correlation factor (R) equal to $100 \%$.

\section{References}

1. Rezaian A. Time-cost-quality-risk of construction and development projects or investment. Middle-East Journal of Scientific Research. 2011; 10(2):218-23.

2. Cheng MY, Tsai HC, Sudjono E. Conceptual cost estimates using evolutionary fuzzy hybrid neural network for projects in construction industry. Expert Systems with Applications. 2010; 37(6):4224-31. https://doi. org/10.1016/j.eswa.2009.11.080

3. A cost estimate system for Gaza Strip construction contractors. Available from: https://iugspace.iugaza. edu.ps/bitstream/handle/20.500.12358/18997/file_1. pdf? sequence $=1$ \&isAllowed $=y$

4. Feng GL, Li L. Application of genetic algorithm and neural network in construction cost estimate. Proceedings of the 2012 2nd International Conference on Computer and Information Application; 2012. p. 1036-9. https://doi. org/10.2991/iccia.2012.254

5. Cavalieri S, Maccarrone P, Pinto R. Parametric vs neural network models for the estimation of production costs: A case study in the automotive industry. International Journal of Production Economics. 2004; 91(2):165-77. https://doi. org/10.1016/j.ijpe.2003.08.005

6. Weckman GR, Paschold HW, Dowler JD, Whiting HS, Young WA. Using neural networks with limited data to estimate manufacturing cost. International Journal of Industrial and Systems Engineering. 2010; 3(4):257-74.

7. Verlinden B, Duflou J, Collin P, Cattrysse D. Cost estimation for sheet metal parts using multiple regression and artificial neural networks: A case study. International Journal of Production Economics. 2008; 111(2):484-92. https://doi.org/10.1016/j.ijpe.2007.02.004

8. Flood I, Kartam NJ. Neural networks in civil engineering. I: Principles and understanding. Journal of Computing in Civil Engineering. 1994; 8(2):131-48. https://doi. org/10.1061/(ASCE)0887-3801(1994)8:2(131)

9. Petroutsatou K, Georgopoulos E, Lambropoulos S, Pantouvakis JP. Early cost estimating of road tunnel construction using neural networks. Journal of Construction Engineering and Management. 2011; 138(6):679-87. https://doi.org/10.1061/(ASCE)CO.1943-7862.0000479

10. AL-Zwainy FM, Aidan IAA. Forecasting the cost of structure of infrastructure projects utilizing artificial neural network model (highway projects as case study). Indian Journal of Science and Technology. 2017; 10(20):1-12. https://doi.org/10.17485/ijst/2017/v10i19/108567

11. Cost estimation for building construction projects in Gaza Strip using Artificial Neural Network (ANN). Available from: https://www.semanticscholar.org/paper/CostEstimation-for-Building-Construction-Projects-Shehatto/ b74344c2ec57e61edcad581e1bbf5eb5cb4c92b8

12. Khaleel TAM. Development of the artificial neural network model for prediction of Iraqi express ways construction cost. International Journal of Civil Engineering and Technology (IJCIET). 2015; 6(10):62-76.

13. Parallel distributed processing. Available from: https:// dl.acm.org/citation.cfm?id=104279

14. Artificial Neural Networks: A tutorial. Available from: http://csc.lsu.edu/ jianhua/nn.pdf

15. Shahin MA, Jaksa MB, Maier HR. Artificial neural network based settlement prediction formula for shallow foundations on granular soils. Australian Geomechanics Journal. 2002; 37(4):45-52.

16. Kamruzzaman J, Sarker RA. Artificial Neural Networks: Applications in finance and manufacturing; 2006. p. 1-31. https://doi.org/10.4018/978-1-59140-670-9.ch001

17. Predicting the settlement of shallow foundations on cohesion less soils using back-propagation neural networks. Available from: https://pdfs.semanticscholar.org/8fa0/ b9fc8c0948329d1092c8ad55ed1534182c98.pdf

18. Neural Network Toolbox. Available from: http://cda.psych. uiuc.edu/matlab_pdf/nnet.pdf 